\title{
3
}

\section{UNDERSTANDING \\ MULTISPECIES MOBILITIES}

\section{From mosquito eradication to coexistence}

\author{
Uli Beisel and Carsten Wergin
}

Extensive loss in biodiversity and warming climates mean that the world faces an unparalleled historical situation of global multispecies suffering. In light of this, it is crucial we widen our discussions about social-cultural change in the Anthropocene from narrow human-centred considerations towards more speculative fields of more-than-human relations. One of the most persuasive methods to account for such entangled lifeworlds is found in "multispecies storytelling," a method that recognizes the human and the more-than-human in onto-epistemic partnership (Haraway, 2016). Multispecies stories challenge anthropocentric narratives that tend to depict the bodies of other species as rhetorically passive resources for human appropriation, whether as consumptive commodities in global economies, or as metaphors and symbols in aesthetics and media. Along these lines, the method of "multispecies ethnography" is a vital tool to study and account for ecological assemblages in ways that aim to highlight and address epistemic inequalities (Kirksey and Helmreich, 2010). Important, though, is that more-than-human relations are not considered a harmonious or romantic endeavour. Rather, often the pressing question for humans in morethan-human encounters is about "how to survive"- a question that is more often than not answered with calls for eradication of non-human disease carriers.

Here we focus on mosquito-borne diseases where the question of human survival and non-human extinction has been prominent for many decades. Our aim is to weave insights about the history of malaria and human-mosquito relations in West Africa together with those of a multispecies ethnography of invasive mosquitoes in Germany. Following threads of multispecies mobility, we show how particular human mobility has come to render mosquitoes killable in colonial West Africa. At the same time, we can see how through globalization and warming climates, mosquitoes remain highly active and mobile. We focus on what is considered number four of the " 100 world's worst invasive alien species," 


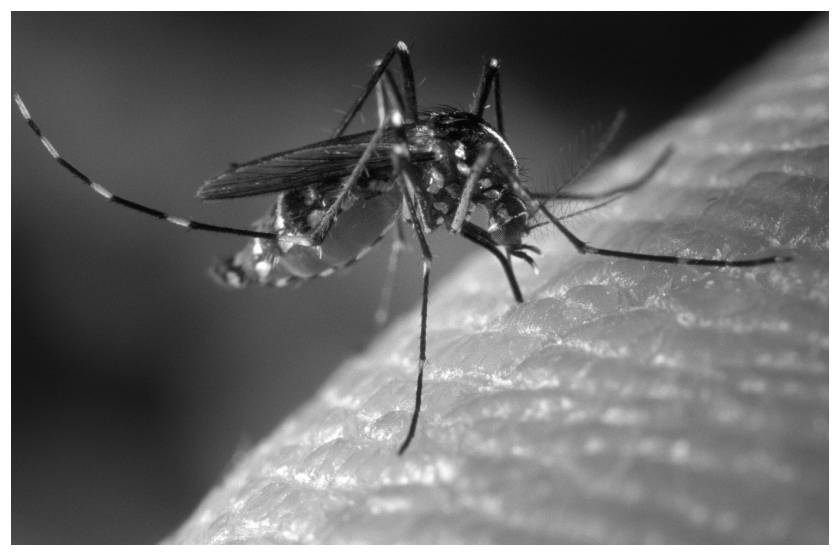

FIGURE 3.1 Asian tiger mosquito (Aedes albopictus). Source:Wikicommons.

the Aedes albopictus (GISD, 2019, see also Kraemer et al., 2019). Ae. albopictus, also known as the "Asian tiger mosquito" due to its striped legs and body, is considered native to the tropical and subtropical areas of Southeast Asia but is today found in many parts of the globe, including Australia, Africa and the Americas (see Figure 3.1). It is an epidemiologically important vector for the transmission of many viral pathogens, including those of yellow fever, dengue and chikungunya. Ae. albopictus can also host the zika virus and potentially transmit it between humans.

It is important to note that Ae. albopictus are considered by the European Centre for Disease Prevention and Control (ECDC)'s Ae. albopictus factsheet as "one of the top 100 invasive species" (ECDC, 2020). It is thus subjected to a rhetoric of "illegality" and "border control" that is enmeshed with global trade, as much as climate change concerns, race and power politics. As Ernwein and Fall show, this border and invasion rhetoric is also utilized in communications about invasive plants (Ernwein \& Fall, 2015). In her work, Fall further shows how this rewrites "the nation state as the most pertinent scale for identity politics" (Fall, 2013: 171). For Ae. albopictus, this tendency is exemplified by a quote from a recent article about the introduction of mosquitoes from Africa to Europe via the Mediterranean Sea. Finding Ae. albopictus caught in traps on Pantelleria, Lampedusa and Linosa, the author presumes links to the arrival of refugees but omits the relevance of global trade for the dispersal of mosquitoes:

Aedes albopictus was found on all three islands under investigation. The consequences on public health with regard to the presence of this mosquito vector and the migrant people entering the country from Africa and the Middle East are also discussed (...) The detection of the Asian tiger mosquito on these islands, which represent the last European strip of land 
facing Africa, has important implications for public health policy and should prompt the national authorities to implement tailored surveillance activities and reinforce plans for preparedness strategies in such contexts.

(Di Luca et al., 2017, emphasis added)

Through this framing, invasive mosquitoes are linked to migrating humans in a problematic way, that is not only dehumanizing and delegitimizing refugees and migrants, but also establishing a wrong, racially charged idea of how invasive mosquitoes travel and extend their habitats. It has been shown in scientific studies that the movement of invasive species is mainly to be linked to traderelated mobility. As the ECDC factsheet also notes, Ae. albopictus are known to travel in used car tyres and "lucky bamboo" (ECDC, 2020). Clearly, economic ties and their diverse technologies of transport are the crucial factor. Yet, human mobilities, from leisure tourism to forced migration, all also have profound impacts on public health. In general, with globalization, mobilities have become more dynamic and complex (Sheller \& Urry, 2006), but also more controllable due to innovations in transportation, border control, media and communication and surveillance technologies. These technologies are actively used in the control of invasive species, which has in the last decade received more attention under the label of biosecurity (Dobson et al., 2013). However, these measures are usually not successful at keeping mosquitoes out of a territory or country. Biosecurity initiatives are in practice rather aimed to control and contain mosquitoes and minimize the disease risk. So, while mosquito eradication has been attempted several times in history, mosquitoes have proven to be good at utilizing human infrastructures and adaptive to changing ecological conditions.

In order to address the complex socio-ecological dynamics at play, there is certainly a need to consider the Asian tiger mosquito as a learning species-a migratory species that makes use of and stimulates social-cultural change, and in doing so reveals problems typical of those of the Anthropocene, such as the prioritization of the economy over planetary health. The movement of the mosquito further calls into question the quest for local eradication strategies while demanding transdisciplinary research partnerships. Increased sightings of the Asian tiger mosquito in Germany have growing potential to generate anxiety in the wider public, since the animals can theoretically transmit a suite of serious infectious diseases (see also Ernwein \& Fall, 2015). At the same time, this mosquito, as a sentinel device older than humans, also offers a form of "radical hope" in our age of global environmental degradation through its capacity to adapt to climate change and counteract violent human efforts to propel it to extinction (Lear, 2006).

In what follows, we draw together historical observations on how anxieties about and reactions to mosquitoes are interlinked, and furthermore, how these have played out in racialized politics of the past. To do so, we initially turn to malaria as a mosquito-borne disease with a well-documented history, recounting certain aspects of the localization of this disease in particular regions of the 
world and imbued with imperial logics that serve to make mosquitoes objects of eradication. We then consider Ae. albopictus and its connection to contemporary questions of mobility, eradication and multispecies coexistence.

\section{Histories of mosquito-human relations}

We believe that when men appeared, mosquitoes were already an ancient form of life, with needles sharpened and adapted to the procurement of vertebrate blood. Very likely too, the mosquito had already formed its close partnership with the protozoan that is the cause of malaria. In what vertebrate the plasmodia first existed as parasites we don't know, but it seems likely that they were not long, as time is measured, in adapting their metabolism to the chemistry of man's cells and fluids. One assumes (...) that disease is as old as life.

(Russell, 1955: 2)

Malaria is one of the most widely known vector-borne diseases across the globe, and it has been so for millennia. Long before health reports started to compile disease mortalities, Indian Vedic texts called malaria "the King of Diseases." Malaria symptoms were outlined in the writings of Hippocrates in fourth century BC Greece, while genetic tests have linked malaria to the death of King Tutankhamun in Egypt. Centuries before, the Chinese treated malaria fever with the qinghão plant, whose active ingredient, artemisinin, remains the standard WHO treatment up to present. Mala aria, medieval Italian for "bad air," reflects how the fever was believed to emanate from unhealthy air in swamps. The etiological significance of air was overturned in the late nineteenth century when French army physician Charles Laveran, working in Algeria, observed Plasmodium parasites in a patient's blood-slides. Ronald Ross, a British Garrison Surgeon working in India, is credited with associating the life cycle of the avian Plasmodium parasite with the Anopheles mosquito.

Despite the historic evidence for the global distribution of this vector-borne disease, and that of mosquitoes as its main "distributor," malaria remains defined by a particular physical and socio-economic geography. Indeed, conceptions of the Global South by European colonialists were deeply influenced by the experience of mosquito-borne diseases. Many colonial accounts speak of bountiful and, at the same time, barren and nasty lands (Blaut, 1993). Such portrayals are firmly influenced by the experiences of struggling with fever and other illnesses. Both tropes - the bountiful and the nasty-were instrumental for justifying colonialism (cf. Blaut: 77). What became popularly known as "the white man's burden" is thus strongly linked to mosquito-borne diseases, which in turn supported a deterministic view of colonial landscapes and their populations, and helped to establish a contrast between so-called natives and Europeans (cf. Arnold, 2000: 81, see also Carlson, 1984: 15-16; Webb, 2014). In other words, perceived differences in vulnerability to vector-borne diseases 
opened the door to violence and racial segregation policies, such that African children, for example, were hypothesized to be disease reservoirs for parasites (Ross, 1910).

Segregation measures ramified across the colonies to find white populations fenced off from African housing, a spatial relationship whose legacies one can still trace through housing developments in what has become known as gated communities (Webb, 2014). Such practices of geographical distancing demonstrate a mutual influence between the wish (and ability) to tame the environment and racial discourses, which are rooted in overtones about the "natural" superiority of one population over another. These discourses also locate the mosquito in some areas but not others. Mosquitoes, infectious diseases, as well as native human populations can all be confined to particular environments where the natural turns nasty, thereby justifying orders to "keep one's distance." The quote from this chapter's introduction demonstrates how racial discourse still impacts our perception of the global spread of mosquitoes. David N. Livingstone adds that in the colonial past, "disease ecology and moral cartography were much closer than distant cousins" (Livingstone, 2002: 173). What is central here is that a rhetoric of invasion and border control attached to the challenges of global containment of Aedes albopictus is still manifested in our political and scientific engagements.

Such long-standing socio-political entanglements of race and society provide the background against which mosquito control mechanisms, from containment to extinction, are conceived and exercised. The following paragraphs discuss how this discourse goes hand in hand with rendering mosquitoes killable and extinction-able. As shown, the history of international malaria control interventions was an integral part of colonial practices that were not only informed by a misunderstanding of the transmission of malaria but were also highly racialized. Indeed, as postcolonial scholars such as Chakanetsa Mavhunga have argued, these interventions stand in contrast with African practices of living with mosquitoes, as colonial rule was introducing, "a new dynamic of relations (...) from co-existence to exterminating the insect" (2018: 12).

In the late nineteenth century, the violent politics of extermination and eradication received new technological tools from imperialist science. The scientific documentation of the Plasmodium parasite and the malaria transmission mechanism laid the foundations for new technological innovations in malaria control. Based on these discoveries, larviciding, screening and the creation of ditches, for instance, became crucial elements of malaria and yellow fever control as in the building of the Panama Canal (Gorgas, 1915; D'Antonio \& Spielman, 2001: 124ff). Further, more elaborate technological innovations were developed during World War II, most notably the malaria drug chloroquine and the insecticide DDT, which eventually led the WHO to officially endorse a Global Malaria Eradication Program (GMEP). To appreciate the importance that the GMEP had for the WHO, it is important to remember that the WHO was founded in 1948 and hence was very much a post-World War II institution, with the GMEP being one of its first major projects. 
But Africa, the continent with most cases of malaria, was not included in the GMEP, partly because of worries about the holoendemic status of malaria in the vast part of sub-Saharan Africa. Experts feared that an incomplete eradication campaign could diminish the acquired partial-immunity of Africans, and this would have resulted in an even greater malaria mortality than before the campaign. As Dobson et al. (2000) argue, the WHO's decision to exclude Africa was based on racial stereotypes about "African monotony" together with the little-understood relationship between endemicity and immunity. Of course, this decision to exclude Africa from the programme also meant that the eradication campaign was in fact never truly global, as its name claimed.

By many indications, the results of GMEP were generally mixed at best, which can also be seen in the abandonment of the programme after a mere 14 years (Packard, 2007). A crucial obstacle for the eradication campaigns that was not considered at the time was related to the adaptability of both mosquitoes and the disease itself. Before 1945 only a dozen species were known to be resistant to pre-DDT insecticides. However, by 1960 already 139 species were reported to be resistant against DDT (Carson, 1962: 234). Thus, the potency of DDT was compromised by the evolution of mosquitoes (cf. Packard, 2007: 155). Countries that managed to achieve eradication mostly lay in sub-tropical climates with unstable, seasonal disease transmission; the only high-transmission regions that managed to eradicate malaria were island nations. In addition, as shown by historical analyses of malaria elimination in the United States (Humphreys, 2001), in Italy (Snowden, 2006) and in Argentina (Carter, 2007), sustainable reductions in disease incidences came about because of a multifaceted approach, which included not only the killing of the mosquitoes, but comprehensive social, economic and environmental changes. The number of malaria incidences remained low because industrial agriculture brought more distance between humans and mosquitoes, and because there was more investment in healthcare and public welfare. Humphreys quotes a malariaologist of the day, who, judging the effect of the DDT campaign, said that "the best we can claim in this country is that "we kicked a dying dog"" (2002: 149). Comprehensive social treatment of malaria was a must, if the aim was its disappearance; the GMEP's strong reliance on technical tools spelled failure for its eradication campaign.

Still, many other retrospective analyses continue to regard the WHO's eradication campaign as highly successful. This reading of the GMEP praises chemical tools such as DDT, and marginalizes other more complex evaluations and interventions aimed at human-mosquito coexistence (Kelly \& Beisel, 2011). The impact of this other eradication narrative is reflected in contemporary discussions about mosquito control, as well as in the Gates Foundation's push for malaria eradication and as a rationale for the WHO's malaria eradication programme (https://www.who.int/malaria/areas/elimination/en/).

These simplifications of the history of mosquito control in Africa and the first malaria eradication campaign have-by relying on imperial and racial logicsrendered the mosquito killable and eradicable. In addition, while mosquito-borne 
diseases have been present also on the European continent until the beginning of the twentieth century, disease transmission was successfully interrupted through improved health infrastructures (for the case of Italy, see Snowden, 2006). The modernist success against mosquito-borne diseases in combination with the historical narratives described above, has also established a narrative that locates dangerous, infectious disease-carrying mosquitoes in countries of the Global South, and so enables the narrative of a menacing "invasive species" to be extended to mosquitoes. One also sees that eradicating highly mobile, biologically complex mosquitoes that populated the earth long before humans existed, has not been easy. Indeed, the failures of earlier eradication campaigns would encourage more humble attempts in dealing with these ancient pesky creatures. The next section takes up this issue of identifying more effective contemporary mosquito control measures, especially the control of mobile, so-called invasive mosquito species.

\section{A multispecies mobilities approach to Aedes albopictus}

What can be learned from the history of mosquito control in Africa when devising mosquito control in Germany? We suggest that this historical framing requires us to attend to situated practices of multispecies mobility in a socio-ecological way. Contemporary interpretations of mosquito-human relations compare these with human encounters with animals, bacteria and other microorganisms within multispecies entanglements (Whatmore, 2002; Hinchliffe, 2007; Kirksey \& Helmreich, 2010). Here, analyses focus on the interwovenness, or "materialsemiotic knottings" of humans with other forms of life-such as understanding dogs and humans as companion species, and bacteria as constituents of human bodies (Haraway, 2008).

While initial studies centred on the moments "when species meet" (ibid.) or on tracing non-human "presences" in urban centres (Hinchliffe et al., 2005), later studies turned to more troubled forms of multispecies coexistence (Buller, 2008; Collard, 2012; Barua et al., 2013; on insects/mosquitoes: Beisel et al., 2013; Kelly and Lezaun, 2014; Beisel, 2015). As Nading shows for Aedes aegypti in Nicaragua, humans, mosquitoes and dengue virus are deeply entangled so that "changes in bodies reverberate through landscapes, and vice versa" (Nading, 2014: 10).

The view of landscapes and infrastructures as shared lifeworlds of mosquitoes and humans provides a way for understanding mosquito-human relationships in a manner wider than the biter-bitten dyad. But how can one track entangled human-non-human mobility in such a way as to limit our impulses stemming from such loaded terms as "invasiveness" and "eradication" and instead search for ways to live together on a mobile and warming planet? Here we sketch a multispecies approach to dealing with what is considered a new arrival in Germany: the Aedes albopictus mosquito. Just as humans and goods move, disease vectors and pathogens utilize global connectivities to expand their habitat. As the 2020 SARS-CoV-2 pandemic painfully showed, a better understanding of the mobility patterns of disease agents and their vectors is crucial for the early detection 
of outbreaks and their successful containment. The geographical distribution of Aedes mosquitoes has continuously broadened over the last decades, with the many species in this genus spreading to different countries through human activities and transportation. Alongside these mosquitoes, arboviral diseases also moved to unprecedented places.

The Mediterranean Basin offers a case in point. Since the Late Bronze Age, this region has continued to be a global hotspot for trade, transport and migration. As a result, countries surrounding the Mediterranean Sea share not only goods but also common health threats posed by vector-borne diseases transmitted by mosquitoes (Jourdain et al., 2019). Since at least the 1960s, the Asian tiger mosquito's geographical distribution has continuously expanded, a process which stems from increased global travel and trade, urban development and tourism, and also climate-change phenomena, such as changing land use and management. As a result, diseases like dengue or chikungunya are no longer considered restricted to tropical and subtropical regions, and are developing a strong urban component (Jourdain et al., 2019: 10). ${ }^{1}$

After spreading to the United States via imported second-hand automobile tyres from Asia, Ae.albopictus is now found in Mexico's Yucatan Peninsula (Salomón-Grajales, et al. 2012), where dengue is a concern not only for medical entomologists but also for the local tourist industry, which depends on an international draw to its world heritage sites. In 1990-1991, Ae. albopictus were again found in used tyres traded from Georgia (USA) to Italy, having previously emerged in Albania in 1979, arriving there in a shipment of goods from China.

Recent surveys showed that these mosquitoes have now spread across the entire peninsula of Italy, parts of Sicily and Sardinia, and into Switzerland. In late 2007, the first Ae. albopictus eggs were discovered in southwestern Germany (Pluskota et al., 2008), where they continue to arrive via freight transport from Italy and Switzerland. Ae. albopictus migrate along the German A5 motorway and have by now settled in the Rhine-Neckar metropolitan region, which counts approximately 2.4 million inhabitants. In multispecies terms, truck drivers and gardeners have become companion species of mosquitoes. The mosquito's disregard for political and economic borders creates a significant challenge for possible control mechanisms, and places these insects alongside other "hyperobjects" such as $\mathrm{CO}_{2}$ or micro-plastic, which also demand political decisionmaking for crossing and transgressing national borders (Morton, 2013).

Meanwhile, dengue and chikungunya remain a health threat in many African countries. Tanzania is a good example: there, Aedes mosquitoes are so far mainly associated with major urban centres, but Ae. aegypti have recently been shown to have high incidence rates in small towns, too (Kahamba et al., 2020). In early 2005, this species was implicated in a major outbreak of chikungunya in the Indian Ocean, especially in the southern states of India, and in a dengue outbreak in Havelock, a tourist destination in the Andaman and Nicobar archipelago (Sivan et al., 2016). 
This entangled globalization of mobile humans and mosquitoes demands a new research focus on transmission that is fostered by transdisciplinary collaboration. In particular, the increased mobility of the Aedes mosquitoes highlights crucial linkages between humans and non-humans that remain understudied in the traditional fields of entomology, global medicine and health research. Rather than continuing to focus on imperially minded war on nature, or focusing on false localizations of which mosquitoes are "native" or "invasive," sustainable mosquito control in times of climate change will need to learn to account for the interlinked mobilities of humans, mosquitoes and goods, as well as to be adaptive by developing infrastructures accounting for changing multispecies environments.

\section{Infrastructuring multispecies environments}

Societies organize movement through the environment with relatively enduring patterns: namely, infrastructures. However, environments are not passive receivers of infrastructures but actively impact on how the latter come into being. Infrastructuring environments means organizing, knowing and managing a multiplicity of relations (cf. Blok et al., 2016).

As the history of mosquito control aptly shows, the dominance of the eradication approach has not only been more complicated, but also more destabilized through climate change and biodiversity decline. Despite all efforts made in the past, mosquitoes' transgression of political, cultural and economic borders remains a significant challenge with regard to selecting control mechanisms. Most entomologists and disease ecologists prioritize the tracking and monitoring of vector movements. As mentioned earlier, unwittingly aiding vector mobility, travellers, truck drivers and gardeners become Aedes' "companion species" (Haraway, 2005). Such entanglements of species are most visible in the diverse ways in which they share infrastructures. This sharing of truck and train routes, planes, or boating facilities challenges conventional assumptions of how human and non-human species live separate lives in a shared environment. Related to this, categorizations into developed regions vs. emerging regions-us vs. themneed to be replaced by mobile documentation and experiences of place-making. One way to confront health threats arising from the spread of Aedes albopictus and its adaptations to human environments is therefore to become attuned to how human-mosquito entanglements shift due to new infrastructurations in our shared environments, in order to (re)negotiate the arrival of new vector species by recording how local communities perceive and react to mosquito presence.

An increased emphasis on bottom-up and citizen science research can help deliver new information on these changing human-mosquito relations. Helpful here would be a multi-sited approach of "following the mosquito," for example by travelling with trucks from Italy to Germany (cf. Marcus, 1998). Other fields useful for developing multispecies ethnographic interventions are existing surveillance systems that are drawn upon to confront the global 
spread of arboviruses. These surveillance technologies are meant to allow for interdisciplinary collaboration and promote cooperation between academic institutions, regional, national and international government agencies. The focus here is on the main routes of introduction, and on infrastructures such as ports, airports or ground crossings like railway nodes and communication and trade routes, as much as on tourist areas. In Germany, such work has already been conducted by the regional health department Rhein-Neckar-Kreis, the Institute of Dipterology and the mosquito control association (KABS), with emerging international partnerships such as TIGER, the Tri-national Initiative Group of Entomology in Upper Rhine Valley (TIGER, 2019).

Due to Ae. albopictus' affinity to human environments, further crucial research sites include used tyre storage facilities, greenhouses and green urban spaces such as vacant lots. Studies show that mosquitoes move between continents mainly via used tyres and to a lesser extent in lucky bamboo, and that they move within continents via the traffic of roadways, as shown by Ae. albopictus' proclivity to enter vehicles (Jourdain et al., 2019: 12-13).

Added to these trends of mosquito dispersal are micro-level movements, for example in backyards that share watering cans among neighbours. Collaborative analyses between entomologists, ecologists and anthropologists would shed light on the socio-ecological dynamics that stem from these entangled mobilities of

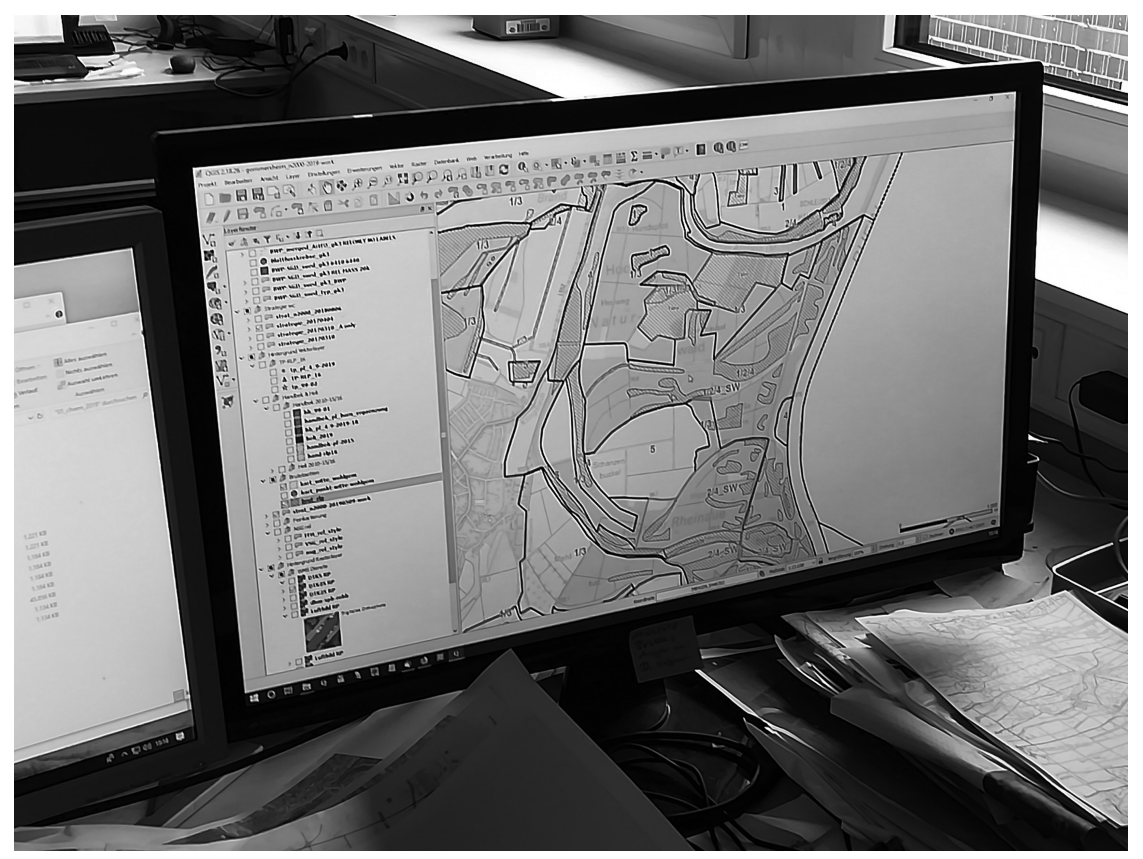

FIGURE 3.2 Computer monitor displaying a section of the Rhine meadows under surveillance. Colour-codes identify the surveillance and control methods used. Source: Carsten Wergin; KABS, https://www.kabsev.de. 
SWR > SWR Aktuell > SWR Aktuell Rheinland-Pfalz

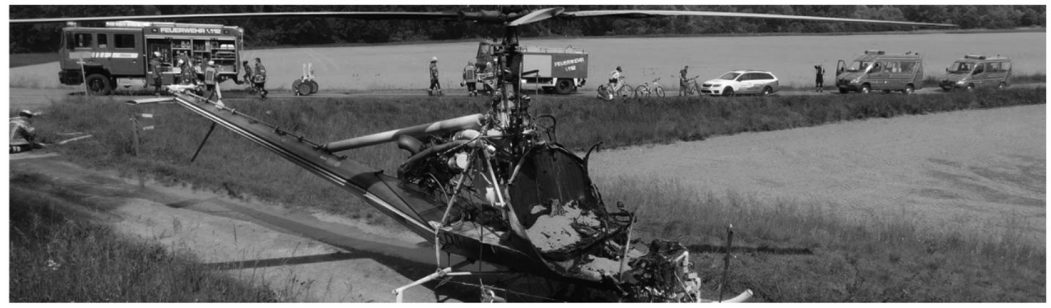

SCHNAKENPLAGE AM RHEIN DROHT

\section{Hubschrauber der Mückenbekämpfer brennt aus}

FIGURE 3.3 Burned-out KAPS helicopter. The translated newspaper headline reads: "Danger of mosquito plague along the Rhine: helicopter of mosquito fighters burns out.” Copyright: SWR.de, 2019.

mosquitoes and humans, offering answers to the question about the role infrastructures play in the transmission of infectious diseases.

Of final concern are the very infrastructures used to study and control the spread of mosquitoes. The control of moving mosquitoes demands that some infrastructures be similarly mobile, since a focus on infrastructures and infrastructural environments means to trace the shifting mobilities of who moves where and when; and whose (im)mobilities engender fresh movement. A spectacular case in point was when the German mosquito control association KABS encountered trouble in June 2019 when it lost control of their helicopter at the peak of the mosquito season (Figure 3.3). This piece of equipment is used to spray the bacteria-produced toxin Bacillus thuringiensis israelensis (Bti) that, if digested, kills the larval stages of vulnerable mosquito species. The helicopter is thus of central importance when it comes to impacting potential mosquito habitat.

In sum, a multispecies approach to mosquito control is necessary because of the impossibility of infrastructuring environments based exclusively on human needs, since environments extend across time and space "involving distributed ecologies typically linking thousands of people, computers, sites, and events" (Blok et al., 2016: 13). Embracing the question of how one can (re)present morethan-human agencies, collectives and collaborations in more equitable terms (Wergin, 2018), the global spread of Ae. albopictus clearly needs to be understood not as yet another unintended effect of capitalist expansionism, but as part and parcel of the continuous "becoming-with" of human and more-than-human actors. In line with this analysis, one can realize that infrastructuring multispecies 
environments will bring us into contact with "two essentially contested 'frontiers': those of the global (environment) and the future (of the collective)" (Blok et al., 2016: 14). Rather than trying to eliminate their presence, we suggest that better understanding their entangled mobilities helps us to work towards socialcultural change and planetary health, since the multispecies story of Aedes albopictus highlights the close entanglement of health, mobility and migration with the "wicked problems" of climate change, extinction and global environmental degradation.

\section{Conclusion}

Many mosquito control interventions have in the past been closely related to the politics of imperial expansion and colonialism. These connections have played heavily on how mosquitoes and human vulnerability to mosquito-borne diseases have been understood. Mosquitoes were not only rendered killable but were also firmly placed in tropical habitats of the Global South, inviting the language of "invasiveness" whenever these creatures moved. Yet one should realize that mosquitoes are older than humans and have always been mobile travellers on this planet. Alongside such facts, one might also remember that most mosquito eradication campaigns have not been very successful. And indeed, where they were successful, careful analysis suggests that changed multispecies infrastructurings were the main factor leading to local demise of the mosquito, and not the techno-fixes of eradication campaigns.

Rather than continuing to set our hopes on a new suite of magic bullets, we suggest that a focus on the entanglements of human and mosquito mobility is urgently needed to detect disease outbreaks early and to develop successful, locally supported control strategies. How are human and mosquito mobilities linked? What methods are most suitable to understand their entanglements and develop more successful control measures? Ae. albopictus has shown tremendous resilience in adapting to different geographical and climatic conditions by taking advantage of human-made environments and infrastructures, which has led to its successful global spread. These anthropogenic environments warrant surveillance at points of entry to understand introduction pathways, causes and routes of invasions and connect these to different aspects of its biology and ecology. Yet, a systematic transdisciplinary collaboration that combines research strands on human, vector and viral mobility is still rare.

Such transdisciplinary endeavours point to the fact that humanity is itself an enterprise that needs rethinking. Understanding human-mosquito movements through effective global partnerships among affected communities requires close collaboration between entomologists, social scientists, technologists and the communities themselves for jointly and systematically developing transdisciplinary methodologies based on comparative data analysis of human and mosquito mobilities. Since the fast-paced spread of Ae. albopictus is intertwined with international trade and human mobility, we believe that intervention to slow or halt its spread is 
possible. Its control, however, needs in-depth analyses of multispecies coexistence, rather than a continued focus on eradication of unwanted companion species.

\section{Note}

1 For example, an average January temperature of $0^{\circ} \mathrm{C}$ was usually considered the survival threshold for Aedes albopictus diapausing eggs. However, the species was found in Trento (Italy) despite minimum temperatures of $-10^{\circ} \mathrm{C}$ and an average January temperature of $-5^{\circ} \mathrm{C}$ (Jourdain et al., 2019: 14)

\section{Bibliography}

Arnold D. 2000. Science, Technology and Medicine in Colonial India. The New Cambridge History of India. Cambridge: Cambridge University Press.

Bartumeus F., Costa G.B., Eritja R., Kelly A.H., Finda M., Lezaun J., Okumu F., Quinlan M.M., Thizy D.C., Toé L.P. \& M. Vaughan 2019. Sustainable innovation in vector control requires strong partnerships with communities. PLOS Neglected Tropical Diseases 13(4): e0007204.

Barua, Maan, Shonil A. Bhagwat, and Sushrut Jadhav. 2013. The Hidden Dimensions of Human-Wildlife Conflict: Health Impacts, Opportunity and Transaction Costs. Biological Conservation 157: 309-16.

Becker N., Pluskota B., Kaiser A. \& F. Schaffner 2012. Exotic mosquitoes conquer the world. In: H. Mehlhorn (ed.) Arthropods as Vectors of Emerging Diseases (Parasitology Research Monographs 3). Berlin: Springer, pp. 31-60.

Beisel, Uli, Ann H. Kelly, and Noémi Tousignant. 2013. Knowing Insects: Hosts, Vectors and Companions of Science. Science as Culture 22(1): 1-15.

Beisel U. 2015. Markets and mutations: Mosquito nets and the politics of disentanglement in global health. Geoforum 66: 146-155.

Bessaud M., Peyrefitte C.N., Pastorino B.A., Tock F., Merle O., Colpart J.J., et al. 2006. Chikungunya virus strains, reunion Island outbreak. Emerging Infectious Diseases 12: 1604-1606.

Blaut J.M. 1993. The Colonizer's Model of the World. Geographical Diffusionism and Eurocentric History. New York: Guilford.

Blok A., Nakazora M. \& B.R. Winthereik 2016. Infrastructuring environments. Science as Culture 25(1): 1-22.

Buller H. 2008. Safe from the Wolf: Biosecurity, Biodiversity, and Competing Philosophies of Nature. Environment and Planning A 40(7): 1583-97.

Carlson D. 1984. Africa Fever: A Study of British Science, Technology and Politics in West Africa, 1784-1864. Canton: History Publications USA.

Carson R. 1962. Silent Spring. Boston, MA: Houghton Mifflin Company.

Carter E. 2007. Development narratives and the uses of ecology: Malaria control in Northwest Argentina, 1890-1940. Journal of Historical Geography 33: 619-650.

Cohen S.A., T. Carson \& M. Thulemark 2015. Lifestyle mobilities: The crossroads of travel, leisure and migration. Mobilities 10(1): 155-172.

Collard, Rosemary-Claire. 2012. Cougar-Human Entanglements and the Biopolitical Un/Making of Safe Space. Environment and Planning D: Society and Space 30(1): 23-42. https://doi.org/10.1068/d19110.

D'Antonio M. \& A. Spielman 2001. Mosquito: A Natural History of Our Most Persistent and Deadly Foe. New York: Hyperion. 
Di Luca M., Toma L., F. Severini et al. 2017. First record of the invasive mosquito species Aedes (Stegomyia) albopictus (Diptera: Culicidae) on the southernmost Mediterranean islands of Italy and Europe. Parasit Vectors 10(1): 543. Published 2017 Nov 2. doi:10.1186/s13071-017-2488-7

Dobson A., K. Barker \& S.L. Taylor. 2013. Biosecurity: The Socio-Politics of Invasive Species and Infectious Diseases. Abingdon: Routledge.

Dobson M.J., Malowany M. \& R.W. Snow. 2000. Malaria control in East Africa: The Kampala conference and the Pare-Taveta scheme: A meeting of common and high ground. Parassitologia 42(1/2): 149-166.

European Centre for Disease Prevention and Control. 2020. Aedes Albopictus - Factsheet for Experts. https://www.ecdc.europa.eu/en/disease-vectors/facts/mosquito-factsheets/ aedes-albopictus (accessed 31/08/2020).

Ernwein M. \& J.J. Fall 2015. Communicating invasion: Understanding social anxieties around mobile species. Geografiska Annaler: Series B, Human Geography 97(2): 155-167.

Fall J.J. 2013. Beyond the nativism debate. Biosecurity: The Socio-Politics of Invasive Species and Infectious Diseases 167-181.

Faulconbridge J. \& A. Hui. 2016. Traces of a mobile field: Ten years of mobilities research. Mobilities 11(1): 1-14.

Gorgas W.C. 1915. Sanitation in Panama. New York: Appleton.

Haraway, Donna Jeanne. 2005. The Companion Species Manifesto. Dogs, People, and Significant Otherness. 3rd printing. Chicago, Ill.: Prickly Paradigm Press, 8.

Haraway D.J. 2008. When Species Meet. Minneapolis, MN: University of Minnesota Press.

Haraway D. 2016. Staying with the Trouble: Making Kin in the Chthulucene. Durham: Duke University Press.

Hinchliffe Steve. 2007. Geographies of Nature: Societies, Environments, Ecologies. London: SAGE.

Hinchliffe F., Kearnes, M.B., Degen, M. and Whatmore, S. 2005. Urban Wild Things: A Cosmopolitical Experiment. Environment and Planning D: Society and Space 23(5): 643-658.

Humphreys M. 2001. Malaria: Poverty, Race and Public Health in the United States. Baltimore: JHU Press.

Jourdain F., Samy A.M., Hamidi A., Bouattour A., Alten B., Faraj C. et al. 2019. Towards harmonisation of entomological surveillance in the Mediterranean area. PLoS Neglected Tropical Diseases 13(6): e0007314. https://doi.org/10.1371/journal.pntd.0007314

Kahamba N.F., Limwagu A.J., Mapua S.A., Msugupakulya B.J., Msaky D.S., Kaindoa E.W., Ngowo H.S. \& F.O. Okumu. 2020. Habitat characteristics and insecticide susceptibility of Aedes aegypti in the Ifakara area, south-eastern Tanzania. Parasites E Vectors 13(53).

Kelly A.H. \& Beisel, U. 2011. Neglected malarias: The frontlines and back alleys of global health. BioSocieties, 6: 71-87.

Kelly A.H. \& Lezaun, U. 2014. Urban Mosquitoes, Situational Publics, and the Pursuit of Interspecies Separation in Dar Es Salaam. American Ethnologist, 41(2): 368-83.

Kirksey, S. and S. Helmreich. 2010. The emergence of multispecies ethnography. Cultural Anthropology 25(4): 545-576.

Kraemer M.R., Reiner O., Brady J., Messina M., Gilbert D., Pigott D., Yi K. L. Johnson 2019. Past and future spread of the arbovirus vectors aedes aegypti and aedes albopictus. Nature Microbiology 4(5): 854-863.

Lear J. 2006. Radical Hope: Ethics in the Face of Cultural Devastation. Cambridge, MA: Harvard University Press. 
Livingstone David N. 2002. Race, space and moral climatology: Notes toward a genealogy. Journal of Historical Geography 28(2): 159-180.

Marcus George E. 1998. Ethnography Through Thick and Thin. Princeton: Princeton University Press.

Mavhunga Clapperton Chakanetsa. 2018. The Mobile Workshop: The Tsetse Fly and African Knowledge Production. Cambridge, MA: MIT Press.

Merriman P. \& L. Pearce. 2017. Mobility and the humanities. Mobilities 12(4): 493-508.

Morton T. 2013. Hyperobjects: Philosophy and Ecology After the End of the World. Minneapolis: University of Minnesota Press.

Nading A.M. 2014. Mosquito Trails: Ecology, Health, and the Politics of Entanglement. Berkeley: Univesity of California Press.

Packard R.M. 2007. The Making of a Tropical Disease: A Short History of Malaria. Baltimore: JHU Press.

Pluskota B., Storch V., Braunbeck T., Beck M. \& N. Becker. 2008. First record of stegomyia albopicta (skuse) (diptera: culicidae) in Germany. European Mosquito Bulletin 26: $1-5$.

Ross P. 1910. The Prevention of Malaria. London: J. Murray.

Russell P. 1955. Man's Mastery of Malaria. London: Oxford University Press.

Salomón-Grajales J., Lugo-Moguel G.V., Tinal-Gordillo V.R., de La Cruz-Velázquez J., Beaty B.J., Eisen L., Lozano-Fuentes S., Moore C.G. \& J.E. García-Rejón. 2012. Aedes albopictus mosquitoes, Yucatan Peninsula, Mexico. Emerging Infectious Diseases 18: 525-527.

Sheller M. \& J. Urry. 2006. The new mobilities paradigm. Environment and Planning $A$ 38: 207-226.

Sivan A., Shriram A.N., Sugunan A.P., Anwesh M., Muruganandam N., Kartik C. et al. 2016. Natural transmission of dengue virus serotype 3 by aedes albopictus (skuse) during an outbreak in Havelock Island: Entomological characteristics. Acta Tropica 156: $122-129$.

Snowden F. M. 2006. The Conquest of Malaria: Italy, 1900-1962. New Haven: Yale University Press.

SWR Aktuell. 2019. Hubschrauber der Mückenbekämpfer Brennt aus. https://www.swr.de (Date retrieved: 01 June 2019).

Webb Jr James LA. 2014. The Long Struggle against Malaria in Tropical Africa. Cambridge: Cambridge University Press.

Wergin C. 2018. Policy in the Anthropocene. Glocalism: Journal of Culture, Politics and Innovation 3: 1-16.

Whatmore S.. 2002. Hybrid Geographies: Natures Cultures Spaces. London: Sage.

\section{Web sources}

GISD 2019. http://www.iucngisd.org/gisd/100_worst.php

One Health 2019. http://www.onehealthinitiative.com

TIGER 2019. https://tiger-platform.eu/ 